Section Editor

John J. Millichap, MD

Pearls \& Oy-sters:

\title{
Spontaneous intracranial hypotension and posterior reversible encephalopathy syndrome
}

\section{PEARLS}

- Although rare, cases of posterior reversible encephalopathy syndrome (PRES) secondary to CSF leak and intracranial hypotension have been documented in the literature.

- The pathogenesis of PRES in these settings has been associated with both arterial and venous cerebrovascular dysfunction.

\section{OY-STERS}

- PRES should be suspected in patients with CSF leak who continue to experience headache, visual changes, and altered mentation despite conservative management.

- The mainstay of treatment involves resolution of the CSF leak, typically with an autologous epidural blood patch.

CASE REPORT A 65-year-old woman with no significant medical history was brought to the emergency room after experiencing 2 weeks of band-like occipital headaches and 2 days of progressive mental status changes. Her neurologic examination was significant for decreased alertness, disorientation to time, confabulation, loss of recent and remote memory, diffuse hyperreflexia, and a left Hoffmann sign. MRI of the brain with contrast showed bilateral subdural hygromas, diffuse enhancement of the dura mater, with mild sagging of the brainstem suggestive of intracranial hypotension (figure 1, A and $\mathrm{B})$. MRI of the spine showed a large collection of CSF in the lumbar epidural space (figure $2 \mathrm{~A}$ ); however, the tear site was not identified. EEG also revealed generalized slowing with no evidence of seizure activity. Her mental status continued to deteriorate despite conservative measures such as aggressive hydration, caffeine intake, and bedrest in the Trendelenburg position. A head CT was ordered for worsening mental status and revealed symmetric hypoattenuation of the bilateral parasagittal occipital cortices consistent with PRES (figure $2 \mathrm{~B}$ ), a finding that was not present on the initial MRI. She then received an emergent lumbar epidural blood patch, resulting in dramatic improvement in mental status several hours later. She was discharged without any focal neurologic deficits. An MRI performed 10 days later revealed no evidence of PRES in the occipital region. An MRI of the lumbar spine performed 5 weeks later showed resolution of the fluid collection (figure 3).

DISCUSSION Spontaneous intracranial hypotension $(\mathrm{SIH})$ is a known neurologic condition characterized by occipital headaches, neck stiffness, and altered mentation that results from leakage of CSF through a structural break in the meninges. Distinct abnormalities on MRI support the diagnosis, including diffuse meningeal enhancement, subdural fluid collections, engorgement of the dural sinuses, and downward displacement of the brain that can result in compression of vital structures (figure 1, A and B). Stupor and coma, for example, have been linked to compression of the diencephalon. ${ }^{1}$ While our patient's altered mental status was initially attributed to brain sagging, her clinical deterioration was complicated by a transient occipital hypodensity concerning for PRES (figure 2B). Although rare, cases of intracranial hypotension and PRES have been reported in the literature following iatrogenic dural puncture. We believe this case highlights an unusual presentation of intracranial hypotension and PRES secondary to spontaneous CSF leak.

PRES is a clinical neuroradiologic condition characterized by headache, visual disturbances, seizures, and altered consciousness presenting with radiographic evidence of reversible vasogenic edema. ${ }^{2}$ Classic etiologies of PRES include hypertension, cytotoxic medications, sepsis, preeclampsia or eclampsia, and multiple organ dysfunction. ${ }^{3}$ While the exact pathophysiology is unknown, PRES has been linked to arterial autoregulatory dysfunction and vascular injury. One major theory suggests that PRES is caused by autoregulatory failure secondary to increased perfusion pressure, leading to vasodilation of the cerebral vessels and the subsequent extravasation of fluid into the interstitial space. ${ }^{2}$ The second major theory suggests that PRES is caused by

From the Department of Neurology, University of Texas Health Science Center at San Antonio.

Go to Neurology.org for full disclosures. Funding information and disclosures deemed relevant by the authors, if any, are provided at the end of the article. 

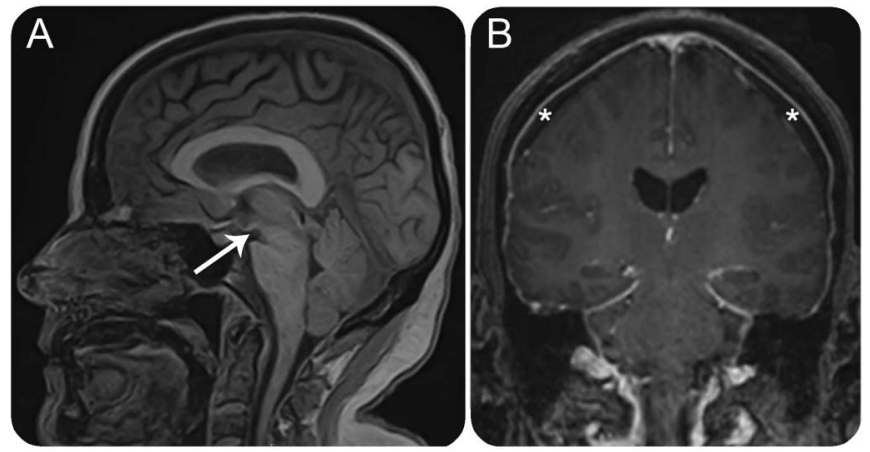

(A) Sagittal T1-weighted view showing severe brain sagging with downward displacement of the interpeduncular cistern (arrow) and mild tonsillar herniation. (B) Coronal T1-weighted view after IV administration of gadolinium showing diffuse pachymeningeal enhancement and subdural fluid collections (asterisks).

endothelial dysfunction from cerebral vasoconstriction during episodes of acute hypertension, leading to decreased cerebral blood flow, ischemia, and edema. ${ }^{2}$ Of note, unlike these classic theories, the pathophysiology of PRES during episodes of intracranial hypotension has been associated with both arterial and venous dysfunction. ${ }^{4-6}$

Regarding arterial abnormalities, several cases suggest that downward displacement of the brain in SIH, along with the subsequent release of chemical and neurogenic factors, can cause transient multifocal vasoconstriction of large and medium-sized arteries. ${ }^{4,7}$ This segmental arterial sclerosis, known as reversible cerebral vasoconstriction syndrome (RCVS), results in transient episodes of ischemia and vasogenic edema. Similar to PRES, the pathophysiology is thought to involve alterations in cerebral vascular

Figure 2 CSF leak with associated occipital hypodensity concerning for PRES
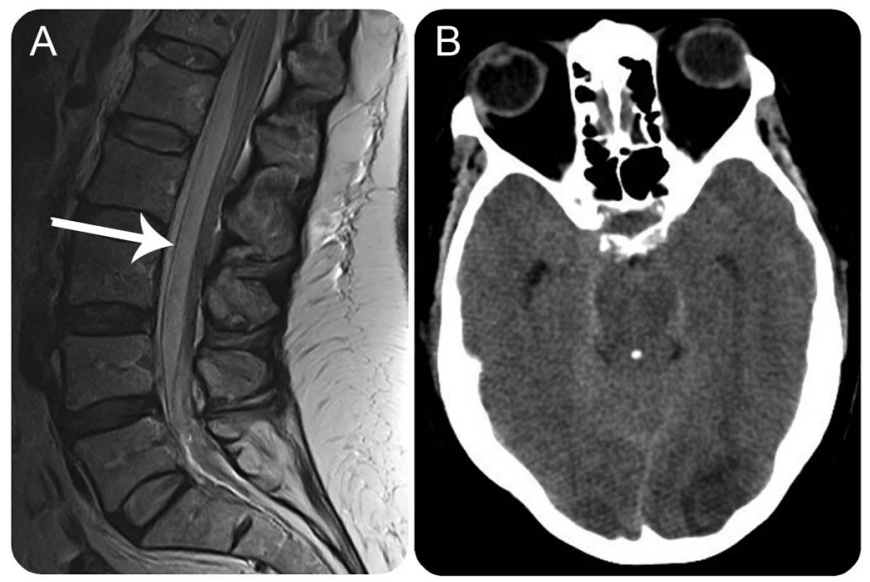

(A) Sagittal T2-weighted view of the lumbosacral spine showing a large collection of fluid in the epidural space (arrow). (B) CT scan of the brain without contrast showing edema of the occipital region consistent with PRES. PRES = posterior reversible encephalopathy syndrome.

\section{collection}

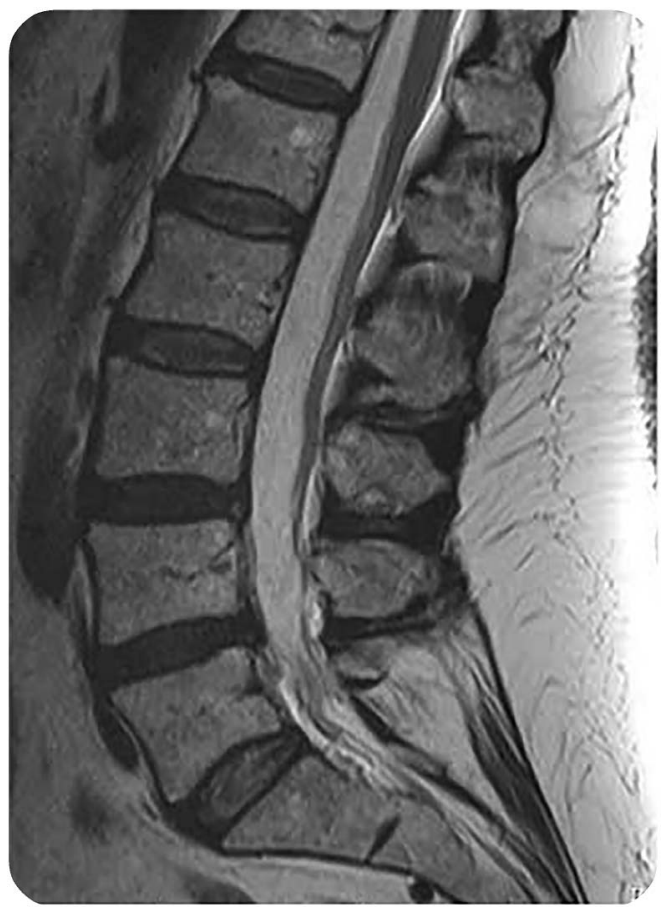

Sagittal T2-weighted view of the lumbosacral spine showing resolution of the CSF collection along the anterior epidural space.

tone. ${ }^{8}$ While RCVS rarely results in cerebral infarction, stroke and deaths have occurred in 2 reported cases of SIH. The cause was unknown but may be secondary to vasoconstriction or mechanical stretching of the arteries due to brain displacement. ${ }^{9}$

We found only 3 case reports of intracranial hypotension and PRES following CSF leak that have directly cited venous dysfunction in the pathogenesis of PRES. ${ }^{4-6}$ Two mechanisms could explain this phenomenon. First, brain perfusion depends on both systemic mean arterial pressure (MAP) and intracranial pressure (ICP), the difference of which determines cerebral perfusion pressure $(\mathrm{CPP})$ : $\mathrm{CPP}=\mathrm{MAP}-$ ICP. In response to CSF loss and intracranial hypotension, the body may compensate by increasing cerebral perfusion pressure. ${ }^{5}$ In extreme states, this hyperperfusion could result in autoregulatory failure consistent with the classic model of PRES. Furthermore, according to the Monro-Kellie doctrine, the cranium contains a fixed volume of brain tissue, blood, and CSF. To maintain euvolemia, a decrease in CSF volume requires a compensatory increase in brain or blood volume. ${ }^{1,46}$ Thus, if increased cerebral perfusion cannot adequately compensate for CSF loss, blood may then pool in the distensible veins and venous sinuses. Anatomical displacement of the brain may also contribute to venous stagnation. Brain sagging has been linked to functional stenosis of the vein of Galen, 
causing impaired venous drainage into the straight sinus. ${ }^{1}$ An increase in venous blood volume may also lead to passive overdistension of the cerebral veins and arterioles, leading to the interstitial extravasation of fluids into the vertebrobasilar vascular territory. This vasogenic edema is consistent with the radiographic signs of PRES.

In the case of our patient, PRES was suspected after several days of worsening mentation and headache in the setting of new radiologic findings. Because the association between SIH and PRES is relatively rare, the differential diagnosis included infection, stroke, and cerebral venous sinus thrombosis. However, labs excluded CNS infection, neuroimaging was negative for ischemic or hemorrhagic infarcts, and her symptoms resolved shortly after blood patching, making venous sinus thrombosis less likely. CT angiography was performed and RCVS was excluded. This syndrome is less likely to occur in our patient because she experienced a progressive onset of symptoms and did not present with thunderclap headache or focal neurologic findings consistent with episodes of transient ischemia. In addition, there were no other apparent causes of PRES as our patient was only mildly hypertensive $(140 / 70 \mathrm{~mm} \mathrm{Hg})$ and denied exposure to medications or toxic substances. PRES has been reported in a case of dural puncture headache following treatment with IV caffeine thought to induce cerebral vasoconstriction. Although our initial management involved caffeine, our patient only consumed minimal amounts by mouth. ${ }^{10}$ Thus, we believe it is possible that PRES was due to autoregulatory dysfunction from a combination of hyperperfusion, venous pooling, and overdistension of the vasculature in an attempt to compensate for lost CSF.

Although the typical presentations of PRES are well defined, variability can exist. We think it is important to recognize the association between $\mathrm{SIH}$ and PRES in order to encourage prompt diagnosis. If PRES is suspected following a spontaneous CSF leak, an emergent blood patch should be performed. We also recommend tight blood pressure control in patients with CSF leak because they may be more susceptible to developing PRES with normal or slightly elevated values, as evidenced in this case. ${ }^{5}$

\section{AUTHOR CONTRIBUTIONS}

Alejandro Santillan: study concept or design, analysis or interpretation of data, accepts responsibility for conduct of research and will give final approval, acquisition of data. Whitley Aamodt: drafting/revising the manuscript, study concept or design, analysis or interpretation of data, accepts responsibility for conduct of research and will give final approval, acquisition of data. Ratna Bhavaraju-Sanka: drafting/revising the manuscript, accepts responsibility for conduct of research and will give final approval.

\section{STUDY FUNDING}

No targeted funding reported.

\section{DISCLOSURE}

The authors report no disclosures relevant to the manuscript. Go to Neurology.org for full disclosures.

\section{REFERENCES}

1. Savoiardo M, Minati L, Farina L, et al. Spontaneous intracranial hypotension with deep brain swelling. Brain 2007; 130:1884-1893.

2. Rykken JB, McKinney AM. Posterior reversible encephalopathy syndrome. Semin Ultrasound CT MR 2014;35: 118.

3. Fugate JE, Claassen DO, Cloft HJ, et al. Posterior reversible encephalopathy syndrome: associated clinical and radiologic findings. Mayo Clin Proc 2010;85:427-432.

4. Pugliese S, Finocchi V, Borgia ML, et al. Intracranial hypotension and PRES: case report. J Headache Pain 2010;11:437-440.

5. Hammad T, DeDent A, Algahtani R, et al. Posterior reversible encephalopathy syndrome secondary to CSF leak and intracranial hypotension: a case report and literature review. Case Rep Neurol Med 2015;2015:538523.

6. Shah R, Kubisz-Pudelko A, Reid J. Posterior reversible encephalopathy syndrome following an inadvertent dural puncture during an emergency laparotomy for ischemic colitis: a case report. Local Reg Anesth 2014;7:1-4.

7. Schievink WI, Maya MM, Chow W, et al. Reversible cerebral vasoconstriction in spontaneous intracranial hypotension. Headache 2007;47:284-287.

8. Schwedt TJ, Matharu MS, Dodick DW. Thunderclap headache. Lancet Neurol 2006;5:621-631.

9. Schievink WI. Stroke and death due to spontaneous intracranial hypotension. Neurocrit Care 2013;18:248-251.

10. Ortiz GA, Bianchi NA, Tiede MP, et al. Posterior reversible encephalopathy syndrome after intravenous caffeine for post-lumbar puncture headaches. Am J Neuroradiol 2009;30:586-588. 


\section{Neurology}

\section{Pearls \& Oy-sters: Spontaneous intracranial hypotension and posterior reversible encephalopathy syndrome}

Alejandro Santillan, Whitley Aamodt and Ratna Bhavaraju-Sanka

Neurology 2016;86; e55-e57

DOI 10.1212/WNL.0000000000002349

\section{This information is current as of February 8, 2016}

\section{Updated Information \&} Services

References

Subspecialty Collections

Permissions \& Licensing

Reprints including high resolution figures, can be found at: http://n.neurology.org/content/86/6/e55.full

This article cites 10 articles, 1 of which you can access for free at: http://n.neurology.org/content/86/6/e55.full\#ref-list-1

This article, along with others on similar topics, appears in the following collection(s):

All Clinical Neurology

http://n.neurology.org/cgi/collection/all_clinical_neurology

Coma

http://n.neurology.org/cgi/collection/coma

MRI

http://n.neurology.org/cgi/collection/mri

Other cerebrovascular disease/ Stroke

http://n.neurology.org/cgi/collection/other_cerebrovascular_disease_s troke

Information about reproducing this article in parts (figures,tables) or in its entirety can be found online at:

http://www.neurology.org/about/about_the_journal\#permissions

Information about ordering reprints can be found online:

http://n.neurology.org/subscribers/advertise

Neurology ${ }^{\circledR}$ is the official journal of the American Academy of Neurology. Published continuously since 1951, it is now a weekly with 48 issues per year. Copyright () 2016 American Academy of Neurology. All rights reserved. Print ISSN: 0028-3878. Online ISSN: 1526-632X.

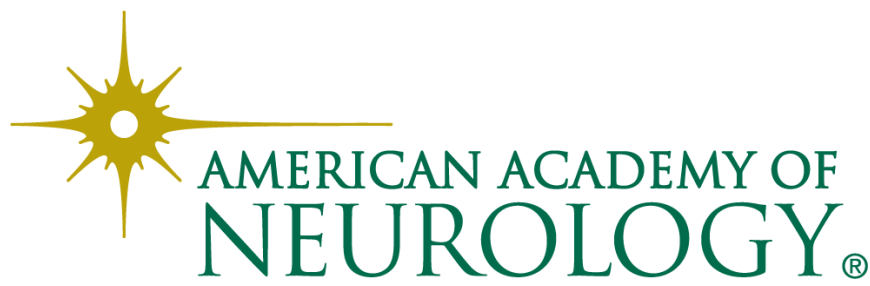

